\title{
Cleaning Efficiency Researches in the Cyclone with Curved Channels from Different Size Particulate Matter
}

\author{
Petras Vaitiekūnas, Egidijus Petraitis, Aleksandras Chlebnikovas \\ Department of Environmental Protection, Vilnius Gediminas technical University, \\ Sauletekio ave. 11, 10223 Vilnius, Lithuania
}

\begin{abstract}
The investigated next-generation multichannel cyclones are designed installing the tangential air flow inlet by means of aerodynamic characteristics of cyclones with the productivity and the efficiency higher than the conventional cyclone devices. These devices with considerably improved construction over conventional cyclones analogue are used for dry particles separation from the gas-air flow. Designed cyclone the gas cleaning device having a curvilinear channels, which can clean up the contaminated air stream from small-sizes particulate matter (PM), in addition to being easy to install and operate. The aim of the described research - to analyze of the cyclone with curved channels cleaning efficiency dependence on the particle dispersity and their different nature. These studies were tested for particulate eliminating efficiency under dispersity dependence, varying inlet air flow velocity in the cyclone. Investigated $1 \mu \mathrm{m}, 2 \mu \mathrm{m}$, $5 \mu \mathrm{m}$ and $10 \mu \mathrm{m}$ size glass, technical salt and clay PM, with bulk densities respectively $2500 \mathrm{~kg} / \mathrm{m}^{3}, 2100 \mathrm{~kg} / \mathrm{m}^{3}, 1700 \mathrm{~kg} / \mathrm{m}^{3}$. Investigating the efficiency of the change were examined $2 \mathrm{~g} / \mathrm{m}^{3}$ and $5 \mathrm{~g} / \mathrm{m}^{3}$ contaminants in polluted air flow levels. It was found that the $10 \mu \mathrm{m}$ size glass PM eliminating efficiency cyclone separator at $5 \mathrm{~g} / \mathrm{m}^{3}$ and $20 \mathrm{~m} / \mathrm{s}$ inlet velocity is $69 \%$.
\end{abstract}

Keywords: cyclone separator; particulate matter; cleaning efficiency; curved channel.

\begin{tabular}{|l|}
\hline Nomenclature \\
$\Delta \mathrm{D}_{\mathrm{f}} \quad$ dispersion composition of particulate matter \\
$\mathrm{PM} \quad$ particulate matter \\
Greek symbols \\
$\rho \quad$ bulk density
\end{tabular}

\section{Introduction}

Cyclones are used for various purposes, but mainly cortical phase separation in multi-phase flow. The flow in the cyclone inlet through the various forms of the inlet can be axial or tangential [1,2]. Tangential inflow is widely used to separate particulate matter from the gas stream $[3,4]$.

Since the middle of twentieth century continuing growth of the industry has forced the world to think of humanity on a new ecological culture necessary to maintain public health needs. Localized particulate matter (PM) emissions of industrial gases (air) flows from the source-one of the most disturbing modern environmental problems.

Cyclones work by centrifugal forces. Fluid mixture enters the cyclone, rotates, and centrifugal forces exposed to dense phase mixture begins to move relatively in the radial direction and is separated from the main flow. It is difficult to analyze this question, since the flow is influenced by many other parameters.

The emissions of contaminated PM in the gas flow cleaning problems are still relevant for atmospheric protection task. Particulate matter pollution affects air quality degradation and may cause human diseases of eyes, skin and respiratory tract, blood vessels and heart disease increases.

One of the problems in the calculation of the efficiency of the cyclone is a flow efficiencies. Generally speaking, large cyclones flow type is turbulent, and the alleged friction factors and the corresponding results are significant. But this is not the small cyclones, where the flow can be important, and operating conditions such as speed, temperature, pressure, viscosity, or the diameter of the cyclone, because according to $[5,6]$, these cyclones flow can be laminar, turbulent, or

Corresponding author: Aleksandras Chlebnikovas. E-mail address: aleksandras.chlebnikovas@vgtu.lt

http://dx.doi.org/10.3846/enviro.2014.066

(C) 2014 The Authors. Published by VGTU Press. This is an open-access article distributed under the terms of the Creative Commons Attribution License, which permits unrestricted use, distribution, and reproduction in any medium, provided the original author and source are credited. 
transition. Flow, which is turbulent, the beginning may become laminar. Laminar flow operating parameters have a greater influence on cyclone efficiency than the case of turbulence. Small cyclones extremely difficult to predict the flow regime on efficiency and pressure losses compared with the effect of geometrical parameters [2].

Computational fluid dynamics (SFD) is a potential tool to characterize the flow fields, particle trajectories, gaseous pollutants [7] and the pressure drop cyclones inside predict [8].

The lack of two-phase flow process of understanding the essence of the cyclone, which could improve the operation is due to the fact that, despite its apparent simplicity, flow dynamics of cyclones is complex and includes such features as a whirling movement, and in some cases several backflow circular area. Closed-vortex-flow theory has so far not been able to isolate a number of features of the flow field. The problem relates to the detailed flow structure of mathematical modeling involves closely related to the mass and momentum conservation of linear partial differential equations and not analytical solution. In addition, the assessment is based on the turbulence isotropy assumption (e.g. turbulent viscosity hypothesis) can not be adapted quickly swirling flows [9]. A similar opinion is expressed and at work [10].

Work [11], the time-averaged Navier-Stokes equations for the gas phase, coupled with anisotropic turbulence model in combination with a k- $\varepsilon$ model and algebraic stress equations. Several studies have modeled the turbulence in order to improve the speed and predictability of pressure modification of turbulence models. All of these studies adopted the axial symmetry, allowing the use of a two-dimensional model, where the solid phase due to the low inlet concentration almost does not gas field.

Cyclones - air cleaning equipment, operation, based on centrifugal forces, which vary depending on the characteristics of a moving air stream. Air flow rate, temperature and pressure affect the movement of air traffic to the nature, changing aerodynamic forces. These studies are relevant to the analysis of the air flow dynamic pressure distribution, selecting the most appropriate case, simplifying six-channel cyclone efficiency setting, multiphase flow of air cleaning, air cleaning will set cleaning efficiency at different PM size [12].

Cyclones are incomparable leaders, including polluted air particulate matter in water treatment plants. Cost, ease of maintenance and equipment issues cyclones not smooth. Due to the specific structure, which has no moving parts and no filtering surface, requiring constant maintenance, comparatively low aerodynamic resistance and high efficiency cyclones to remain competitive in today's market for a long time [13, 14].

Examining multi-cyclone with adjustable half-rings were analyzed different dispersion of particulate removal from air traffic multi-channel cyclone efficiency. It was studied from $1 \mu \mathrm{m}$ to $10 \mu \mathrm{m}$ aerodynamic diameter PM eliminating efficiency.

Cyclone type air cleaning devices are mainly used in industries that have high emissions of polluted air flow volumes. Most of the equipment is only suitable for PM separation in high-dispersity multi-phase flow. Enhanced six-channel cyclone structure designed and small-dispersity PM to $10 \mu \mathrm{m}$ to separate [3], [12, 13].

There are currently many designed cyclones, which are used not only in industry but also the power facilities and agriculture. Recent create cyclones are patented, which differs in its originality, but still the main distinguishing feature of the performance of the equipment-vortex flow. Commonly used in structural parts cyclones are designed, according to the diameter of the cyclone [15].

Cyclones are used as a drying apparatus, reactors and catalysts. Cyclone efficiency, speed and pressure settings required for qualified industry professionals in the knowledge of the flow of gas in a cyclone.

Simple cyclone design has essentially remained unchanged for more than a century. There are two main types of structures cyclone: cyclone direct and reverse flow cyclone. However, the most commonly used backflow, which are further divided into: axial flow and rotary flow cyclones with tangential introduction of gas into the cyclone body [13, 14].

It is assumed that the cleaning efficiency of the poly-dispersed system distributed according to the logarithmic-normal dependence. The overall cleaning efficiency can be calculated by the following formulas:

$$
\begin{aligned}
& \eta=\frac{1}{\sqrt{2 \pi}} \int_{-\infty}^{x} e^{-\frac{t^{2}}{2}} d t, \\
& x=\frac{\lg d_{m} / d}{\sqrt{\lg ^{2} \delta_{T}+\lg ^{2} \delta}},
\end{aligned}
$$

where: $\mathrm{d}_{\mathrm{m}}-$ median size distribution with probability $f(\delta), m, \lg \delta$ - root mean square of logarithmical particle sizes, $\lg \delta_{\mathrm{T}}-$ cyclone parameter efficiency by turbulent index, $t$ - time, $\mathrm{s}, x$-efficiency parameter.

Patterson and Munz [16] studied dependances of PM concentration and temperature from 300 to $2000 \mathrm{~K}$, the gas inlet velocity of 3 to $42 \mathrm{~m} / \mathrm{s}$ and PM concentrations up to $235.2 \mathrm{~g} / \mathrm{m}^{3}$ effects of cyclone collection efficiency and found that the PM concentration increases the collection efficiency especially at high temperatures [13], [17].

In the present cyclone air cleaning efficiency studied at a relatively small PM in polluted air concentrations. Experimental subjects in the scientific literature, are to be found work at concentrations from $1.0 \mathrm{~g} / \mathrm{m}^{3}$ to $25 \mathrm{~kg} / \mathrm{m}^{3}$.

Cyclone separators operate under centrifugal forces and filtration. Fluid mixture enters the cyclone rotates, centrifugal forces and exposed to a mixture of densified relative phase starts to move in the radial direction and is separated from the main flow. This question is difficult to analyze, because in addition to the three-dimensional nature of the flow influenced by many other parameters [2]. 
In the last year the company started using the multi-channel-cyclone filters [14]. High efficiency cyclones and filters used to reduce dust in the industry. Two major cyclone parameters, collection efficiency and pressure drop is strongly influenced by the inlet PM concentration [13].

The aim of work - to set air flow settings and to investigate air cleaning efficiency of six-channel cyclone at different PM dispersity at $500 \mathrm{mg} / \mathrm{m}^{3}$ to $10 \mathrm{~g} / \mathrm{m}^{3}$.

\section{Methodology}

The experimental multi-channel spiral cyclone is constructed in the Institute of Environmental Protection of Vilnius Gediminas Technical University (VGTU).

Based on the results of experimental studies are found to be contaminated with the greatest total flow of the cleaning efficiency is achieved by using an equivalent (75\% and $25 \%$ ) among the transit and peripheral flow cyclone channel separation zones. In this way, the peripheral air flow accounted for $75 \%$ of the total flow rate of the channel to the flow separation and transit $-25 \%$. In this case, the cleaning efficiency tests according to the dispersity was performed using the said case in order to determine the optimum cleaning performance parameters.

Enhanced six-channel cyclone for polluted air cleaning efficiency of the experimental setup, the selected PM, which are formed in the industrial production of the processes. The selected PM are quite different in nature, it is done in order to determine the best issue in the air cleaner customization in a particular industry, according to the selected PM physical properties: density, flowability and dispersity - glass $\left(\mathrm{SiO}_{2}\right)$, the bulk density $\left(2500 \mathrm{~kg} / \mathrm{m}^{3}\right)$, technical salt, the bulk density $\left(2100 \mathrm{~kg} / \mathrm{m}^{3}\right)$, clay $\left(\mathrm{Al}_{2} \mathrm{O}_{3} * \mathrm{SiO}_{2} * \mathrm{H}_{2} \mathrm{O}\right)$, the bulk density $\left(1700 \mathrm{~kg} / \mathrm{m}^{3}\right)$.

The present multi-channel cyclone spiral of experimental stand shown on Figure 1.

Two-phase airflow tangentially enters through the airflow inlet (1), (12) and reaches the first cyclone channel (6), which is limited by the peripheral wall and first curvilinear half-ring in the separation chamber (4). The two-phase air flow tangentially flows though inlet and enters first channel of cyclone that is restrained by peripheral wall and first curvilinear half-ring (7). The flow moving from the previous channel encounters half-ring wall and is distributed into two flows in the spacing between the curved channel (8): peripheral and transitional. Part of the peripheral flow moves into repeated filtration in the cyclone; whereas, the transitional flow - into the following channel towards axis of the device and outlet of the cyclone. In this way the airflow is distributed evenly in channels with different curves and is filtered through the spaces between half-rings. The turbulent flow influences the activity of centrifugal forces, and additional filtration effect occurs in flow distribution zone. The overall effect of forces influences precipitation of particulate matter in the conical hopper (11) of six-channel cyclone. The cleaned air which has gone through all six channels (6) of cyclone flows out of the system through the outlet (2), (13). The dusty air is being filtrated in the active zone of channel spaces and in the result of particulate matter interaction when they coagulate.

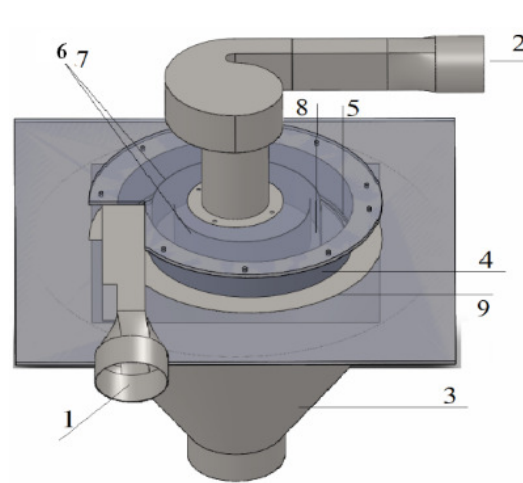

(a)

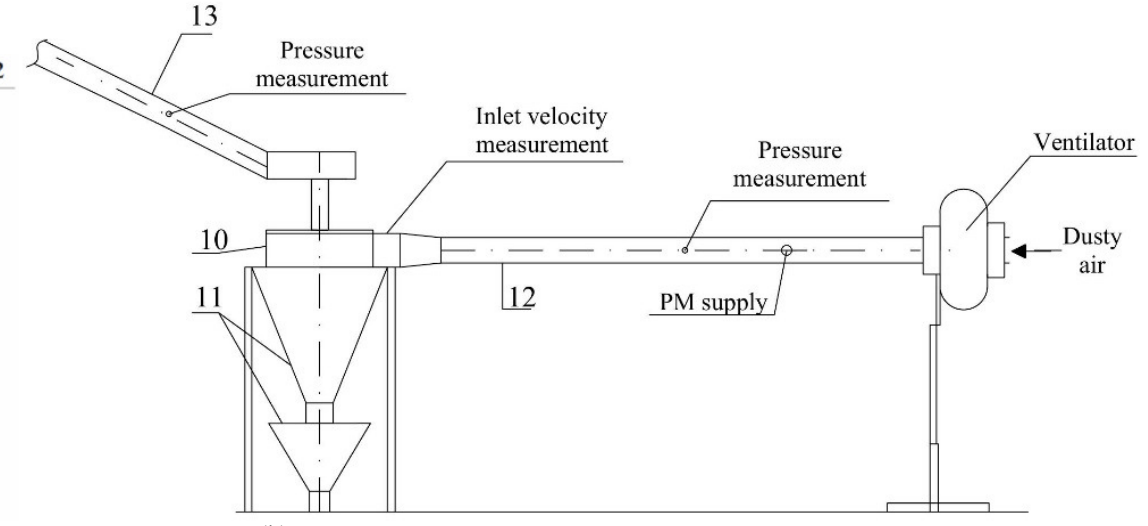

(b)

Fig. 1. Experimental spiral multi channel 3D view (a) and principal scheme (b) of cyclone: 1 - contaminated PM in the air flow inlet and purified air outlet (2), 3 (11) - conical hopper, 4 - spiral-shaped separation chamber with the sectional ring slits (5), 6 - curved channels with different radius cylindrical halfrings (7), 8 - the spacing between the curved channel, 9 - the cyclone spiral casing of the well, 10 - multichannel cyclone, 12 -supplied flow duct, 13 - exhaust flow duct

Experimental study used an air compressor in the „Cosmos“, the working pressure - 10 bar. The compressor is connected to the feed nozzle, which is sucked dust PM directly fed to the incoming air duct cyclone with a diameter of $200 \mathrm{~mm}$, thus providing a biphasic diffuse air flow. Used a fan (RS model NL100), sand spray, Seconda stopwatch (accurate to $\pm 0.2 \mathrm{~s}$ ), a multifunction meter Testo 400 (temperature measuring range $-2-70{ }^{\circ} \mathrm{C}$, accuracy $- \pm 0.2{ }^{\circ} \mathrm{C}$, the speed measuring range $-1-30 \mathrm{~m} / \mathrm{s}$, error $- \pm 0.05 \mathrm{~m} / \mathrm{s}$ ) is connected to a pneumatic tube NIIOGAZ (measurement range of $4-21 \mathrm{~m} / \mathrm{s}$ ), the average value of the tube coefficient $\mathrm{k}=0.70 \pm 0,02$ ), differential pressure gauge DSM-1 (measuring range $0-20 \mathrm{MPa}$, error $- \pm 5 \mathrm{~Pa}$ ) pressure monitoring system changes, eliminating the potential flow unevenness error, the possible distribution of PM dispersed throughout the supply air stream. Particle counter AZ-5 (particle registration range from $0.4-10 \mu \mathrm{m}$, the ambient temperature is between $20-25{ }^{\circ} \mathrm{C}$, atmospheric pressure $750 \pm 30 \mathrm{mmHg}$, the process of relative humidity $-52 \%$ particle concentration measurement range from $10^{-3}$ to $300 \mathrm{~m}^{-3}$, particle flow $-1.2 \mathrm{~L} / \mathrm{min}$, tolerance $- \pm 20 \%$ ). Prior to 
testing, selected particulate samples are dried in a laboratory electric furnace at $80{ }^{\circ} \mathrm{C}$ to constant weight, and then the day considered $24-26{ }^{\circ} \mathrm{C}$ temperature. PM are crushed using Retsch RM200 mill. The second classification of PM during operation-dried PM sieved through sieves 3 and 4 complex, using a vibrating device - shaker samples. Samples are used for bolting 20, 50, 100, 500 micrometre sieve.

Particulate photoelectric aerosol particle counter AZ-5 was used for the PM size distribution (from $1 \mu \mathrm{m}$ to $10 \mu \mathrm{m}$ ) measurements based on the number of particles per liter. The meter works by measuring the individual KD light scatter. Since there is a correlation between size and PM scattered light, as well as the possible PM size distribution measurement. Particle counter consists of an optical detector, air intake and flow control units and electronic assemblies. In order to reduce sampling error, resulting from the cyclone air outlet pipe resulting turbulent flow, which can throw off particles primarily on the external walls of the flow tube fitted Straightening grill.

Given the fed concentrations and determining the number of particles in the air volume is calculated cyclone air cleaning efficiency. The meter is calibrated at to determine particulate emissions, depending on the PM dispersity determined. The unit is controlled by the ranges are changed depending on the particle content of the air volume corresponds to a factor of importance to the PM concentration. Determining particle number, registered counter falling and the outlet of the cyclone unit duct, suggestive of air cleaning efficiency of a certain particle diameter.

\section{Results and discussion}

Determination of $1 \mu \mathrm{m}, 2 \mu \mathrm{m}, 5 \mu \mathrm{m}$ and $10 \mu \mathrm{m}$ PM eliminating efficiency of the cyclone catch samples were tested in three groups - a glass, hardware salt and clay PM. Efficacy was examined at $8 \mathrm{~m} / \mathrm{s}$ and $12 \mathrm{~m} / \mathrm{s}$ and $16 \mathrm{~m} / \mathrm{s}$ and $20 \mathrm{~m} / \mathrm{s}$ inlet velocities to six-channel cyclone. Dispersant PM composition is given in Table 1. Contained the particulate fractions of dispersion composition according to the diameter of the interval in question.

The studies used the most common manufacturing processes PM concentration $-2 \mathrm{~g} / \mathrm{m}^{3}, 5 \mathrm{~g} / \mathrm{m}^{3}$. The most reliable determination of PM concentration results are obtained by taking a sample of the straight duct diameters of 3-4 for the cyclone, where there is no gas flow disturbances: fan, valves and so on. Duct to measure the location selected by the pierced hole and installation of metal $50 \mathrm{~mm}$ nozzles and made $20 \mathrm{~mm}$ aperture.

Table 1. Dispersion composition of particulate matter fractions in question within the range

\begin{tabular}{|c|c|c|c|c|c|c|c|c|}
\hline \multicolumn{9}{|c|}{ Glass particulate matter } \\
\hline $\mathrm{d}, \mu \mathrm{m}$ & $0.0-2.0$ & 2.0-3.0 & $3.0-4.0$ & $4.0-5.0$ & $5.0-7.0$ & $7.0-10$ & $10-15$ & 15-20 \\
\hline$\Delta \mathrm{D}_{\mathrm{f}}, \%$ & 3.07 & 3.59 & 5.43 & 3.83 & 7.65 & 13.53 & 29.13 & 33.77 \\
\hline \multicolumn{9}{|c|}{ Technical salt particulate matter } \\
\hline $\mathrm{d}, \mu \mathrm{m}$ & $0.0-2.0$ & 2.0-3.0 & $3.0-4.0$ & $4.0-5.0$ & $5.0-7.0$ & $7.0-10$ & $10-15$ & 15-20 \\
\hline$\Delta \mathrm{D}_{\mathrm{f}}, \%$ & 3.26 & 5.99 & 9.81 & 7.16 & 13.22 & 15.95 & 24.20 & 20.41 \\
\hline \multicolumn{9}{|c|}{ Clay particulate matter } \\
\hline $\mathrm{d}, \mu \mathrm{m}$ & $0.0-2.0$ & 2.0-3.0 & $3.0-4.0$ & $4.0-5.0$ & $5.0-7.0$ & $7.0-10$ & $10-15$ & 15-20 \\
\hline$\Delta \mathrm{D}_{\mathrm{f}}, \%$ & 4.41 & 5.42 & 7.53 & 5.03 & 9.01 & 12.89 & 25.57 & 30.14 \\
\hline
\end{tabular}

PM concentrations up to a certain aerodynamic diameter was calculated using the following formula:

$$
C=\frac{a \times b}{100}, g / m^{3}
$$

where: $a$ - total average PM concentration (measured by the weighted method), $\mathrm{g} / \mathrm{m}^{3}, b-$ part of the PM to a certain aerodynamic diameter, \%.

Part of the PM to a certain aerodynamic diameter calculated by the following formula:

$$
B=\frac{d}{e}
$$

where: $d$ - the number of particles up to a certain aerodynamic diameter measured with AZ-5 sample per liter, $e-$ total number of particles in a certain range of the measured AZ-5 per liter.

Using the above devices and methods set small-dispersed PM eliminating of multi-channel cyclone efficiency at different inlet velocity and PM concentration.

Experimental six-channel cyclone cleaning efficiency by dispersity research established PM eliminating efficiency dependence on the different nature of PM, bulk density, concentration and inlet air flow velocity in the cyclone.

The highest bulk density - the glass PM eliminating efficiency of the air flow results at $2 \mathrm{~g} / \mathrm{m}^{3}$, presented in Figure 2 . 


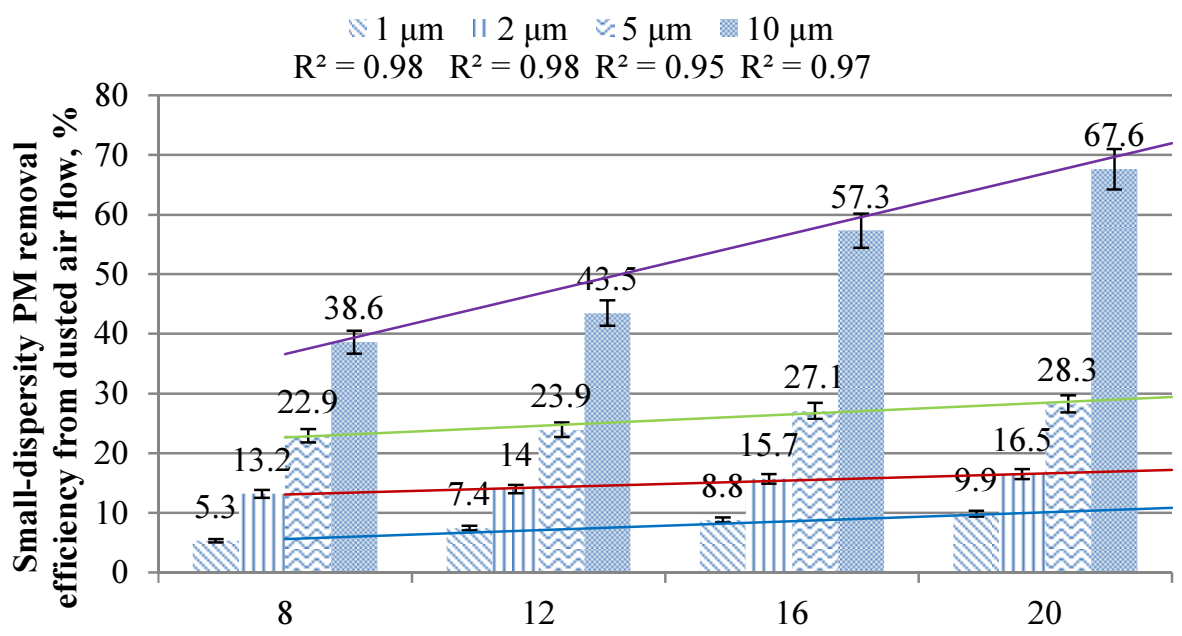

Air flow inlet velocity into cyclone, $\mathrm{m} / \mathrm{s}$

Fig. 2. Efficiency dependencies of eliminating of different size glass $\left(\rho=2500 \mathrm{~kg} / \mathrm{m}^{3}\right) \mathrm{PM}$ from the air in the spiral six-channel cyclone, under concentration of $2 \mathrm{~g} / \mathrm{m}^{3}$ and air flow inlet velocity $(8,12,16,20 \mathrm{~m} / \mathrm{s})$

The results indicate that the $1 \mu \mathrm{m}$ and $2 \mu \mathrm{m}$ PM eliminating efficiency from dusted air flow $-5.3 \%$ and $13.2 \%$ obtained with the minimum air flow rate $-8 \mathrm{~m} / \mathrm{s} .5 \mu \mathrm{m}$ and $10 \mu \mathrm{m}$ PM removal efficiency, respectively $-22.9 \%$ and $38.6 \%$. It may be noted that the removal of $5 \mu \mathrm{m}$ or larger in diameter PM, cleaning efficiency was significantly increased growth of PM aerodynamic diameter of the analyzed air flow rates within the range.

Air speed was increased from $8 \mathrm{~m} / \mathrm{s}$ to $12 \mathrm{~m} / \mathrm{s}$ and $12 \mathrm{~m} / \mathrm{s}$ to $16 \mathrm{~m} / \mathrm{s}$, PM eliminating efficiencies of air traffic increased by approximately $2.2 \%$ and $5 \%$. The biggest change between the cleaning efficiency observed for PM with $5 \mu \mathrm{m}$ and $10 \mu \mathrm{m}$ sizes. Inflow velocity changes from $12 \mathrm{~m} / \mathrm{s}$ to $16 \mathrm{~m} / \mathrm{s}, 10 \mu \mathrm{m}$ PM eliminating efficiency of the air traffic increased over 1.3 times.

At a maximum of $20 \mathrm{~m} / \mathrm{s}$ inlet velocity to the cyclone, PM eliminating efficiencies of air traffic is highest. However, significant change was observed only in the investigation of $10 \mu \mathrm{m} \mathrm{PM}$, when their effectiveness compared with $16 \mathrm{~m} / \mathrm{s}$ inlet velocity case is $10.3 \%$ higher. The examination of the other PM sizes is not significant efficiency gains, of around $1 \%$.Cleaning efficiency is obtained as compared with the cases at $2 \mathrm{~g} / \mathrm{m}^{3}$ than at $5 \mathrm{~g} / \mathrm{m}^{3}$ concentration of PM. Partition dependency is shown in Figure 4. Cyclone efficiency of the smallest size $1 \mu \mathrm{m}$ glass PM is higher at the lowest air flow rate $-8 \mathrm{~m} / \mathrm{s}-7.2 \%$. The amount of PM at $2 \mathrm{~g} / \mathrm{m}^{3}$, cleaning efficiency - reduced by 1.4 times. PM sized $2 \mu \mathrm{m}$ eliminating efficiency of approximately 2.2 times greater than $1 \mu \mathrm{m}$ and PM ranging from $16.1 \%$ to $19 \%$ (Fig. 3 ). $5 \mu \mathrm{m}$ PM at high air flow rate, eliminating efficiency - up to $34.8 \%$, which is 3.5 times higher in terms of the maximum values obtained from the evaluation of $1 \mu \mathrm{m}$ PM eliminating efficiency.

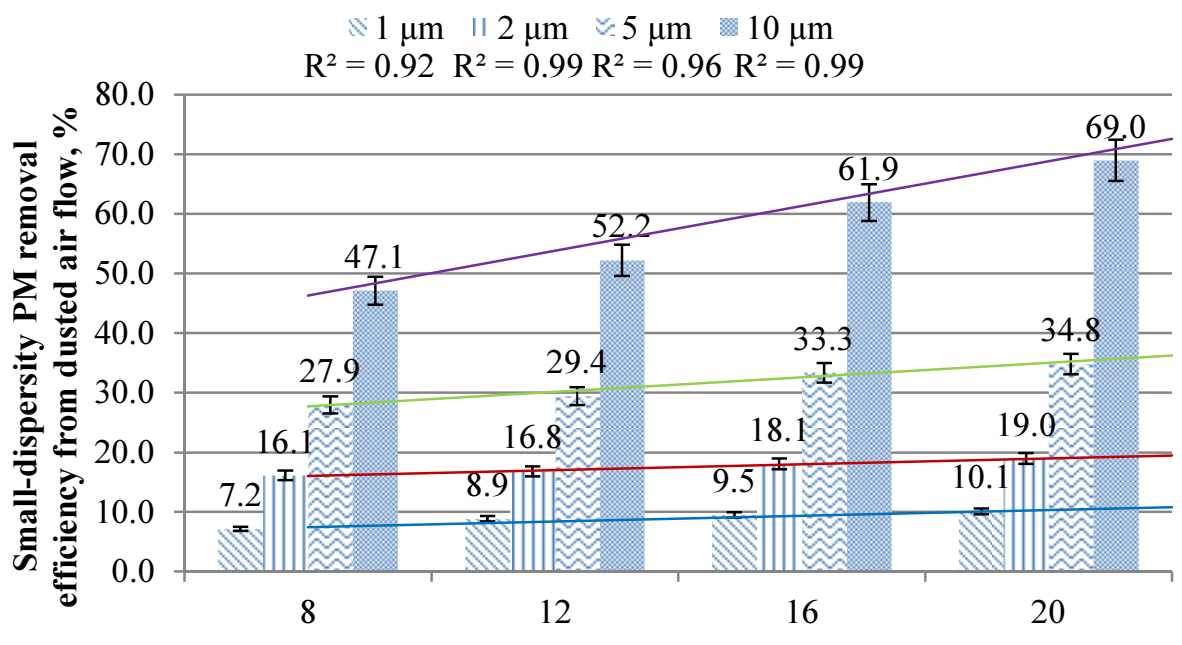

Air flow inlet velocity into cyclone, $\mathrm{m} / \mathrm{s}$

Fig. 3. Efficiency dependencies of eliminating of different size glass $\left(\rho=2500 \mathrm{~kg} / \mathrm{m}^{3}\right) \mathrm{PM}$ from the air in the spiral six-channel cyclone, under concentration of $2 \mathrm{~g} / \mathrm{m}^{3}$ and air flow inlet velocity $(8,12,16,20 \mathrm{~m} / \mathrm{s})$

As in the case at $2 \mathrm{~g} / \mathrm{m}^{3}$, significant changes in the efficiency observed for PM with $5 \mu \mathrm{m}$ and $10 \mu \mathrm{m}$ sizes. At $5 \mu \mathrm{m}$ PM the size of the largest eliminating efficiency change set changes in the inlet velocity of $12 \mathrm{~m} / \mathrm{s}$ to $16 \mathrm{~m} / \mathrm{s}$, the efficiency increase of $3.9 \%$, and $33.3 \%$ were achieved eliminating efficiency value. In all other cases, investigation of $1 \mu \mathrm{m}, 2 \mu \mathrm{m}$ and 
$5 \mu \mathrm{m}$ PM eliminating efficiency increased from $3 \%$ using $1 \mu \mathrm{m}$ PM up to $6.9 \%-5 \mu \mathrm{m}$ PM, increasing air flow into the cyclone inlet velocities from $8 \mathrm{~m} / \mathrm{s}$ to $20 \mathrm{~m} / \mathrm{s}$.

Technical salt PM eliminating efficiency of the air flow results at $2 \mathrm{~g} / \mathrm{m}^{3}$, presented in Figure 4 . The experimental results show that the PM with a diameter of 2 micrometers eliminating of air flow efficiency depends on at least a change in the inlet air flow velocity in the cyclone. In this case, the increased speed of $8 \mathrm{~m} / \mathrm{s}$ to $20 \mathrm{~m} / \mathrm{s}$, the efficiency increased by an average of $2.5 \%$ and $14.5 \%$ equal value. PM in the size range $1 \mu \mathrm{m}$ at $2 \mathrm{~g} / \mathrm{m}^{3}$ when the cyclone inlet velocity was $8 \mathrm{~m} / \mathrm{s}$, eliminating efficiency $-5 \%$. At the maximum $-20 \mathrm{~m} / \mathrm{s}$ air flow inlet velocity, cleaning the air flow efficiency increases to $8.7 \%$, i.e. 1.7 times.

Removal efficiency of $5 \mu \mathrm{m} \mathrm{PM}$ is $19.5 \%$ at $8 \mathrm{~m} / \mathrm{s}$ air flow rate and the air flow rate of $20 \mathrm{~m} / \mathrm{s}$, efficiency increased $6.8 \%$ and $26.3 \%$. Examining a size $10 \mu \mathrm{m}$ removal efficiency changes, it can be said that the air velocity increases from $8 \mathrm{~m} / \mathrm{s}$ to $12 \mathrm{~m} / \mathrm{s}$ and $12 \mathrm{~m} / \mathrm{s}$ to $16 \mathrm{~m} / \mathrm{s}$, PM removal efficiencies of air traffic increased by approximately $5.4 \%$ and $10.7 \%$. The results indicate that the $2 \mu \mathrm{m}$ and $5 \mu \mathrm{m}$ PM removal from the dusted air flow efficiency $-12.1 \%$ and $19.5 \%$ obtained with the minimum air flow rate $-8 \mathrm{~m} / \mathrm{s}$ and $10 \mu \mathrm{m}$ PM removal efficiency and the highest was $-35.5 \%$. Removal efficiency dependence on the inlet air flow velocity in the cyclone is strongest at $1 \mu \mathrm{m}$ and $10 \mu \mathrm{m}$ PM size, these cases a change in speed from $8 \mathrm{~m} / \mathrm{s}$ to $20 \mathrm{~m} / \mathrm{s}$, the efficiency values increased by 1.7 and 1.6 times.

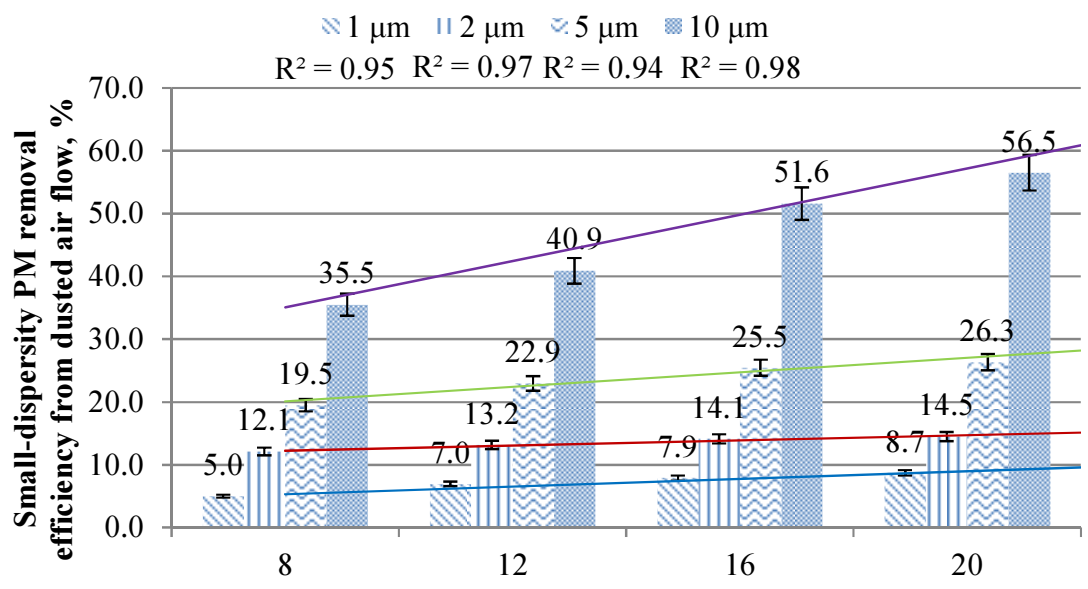

Air flow inlet velocity into cyclone, $\mathbf{m} / \mathbf{s}$

Fig. 4. Efficiency dependencies of removal of different size technical salt $\left(\rho=2100 \mathrm{~kg} / \mathrm{m}^{3}\right)$ PM from the airi $\mathrm{n}$ the spiral six-channel cyclone, under concentration of $2 \mathrm{~g} / \mathrm{m}^{3}$ and air flow inlet velocity $(8,12,16,20 \mathrm{~m} / \mathrm{s})$

Figure 5 present the spiral cyclone efficiency of experimental results using a $5 \mathrm{~g} / \mathrm{m}^{3}$ concentration of PM. In the latter the concentration of PM removal efficiency is obtained as compared with the cases at $2 \mathrm{~g} / \mathrm{m}^{3} .1 \mu \mathrm{m}$ PM removal efficiency of air traffic increased from $8.7 \%$ to $8.9 \%$, compared with the case using $2 \mathrm{~g} / \mathrm{m}^{3}$. The smallest size $-1 \mu \mathrm{m}$ technical salt particulate matter removal efficiency, at a minimum air flow rate of $8 \mathrm{~m} / \mathrm{s}-6.2 \%$. The amount of PM at $2 \mathrm{~g} / \mathrm{m}^{3}$, removal efficiency - reduced 1.2 times. $2 \mu \mathrm{m}$ PM removal efficiency is approximately 2 times greater than $1 \mu \mathrm{m}$ and PM ranging from $14.3 \%$ to $16.3 \%$ (Fig. 6). $5 \mu \mathrm{m}$ PM at high air flow rate, removal efficiency - up to $31.1 \%$, which is 3.5 and 1.9 times higher in terms of the maximum values obtained from the evaluation of $1 \mu \mathrm{m}$ and $2 \mu \mathrm{m}$ PM removal efficiency.

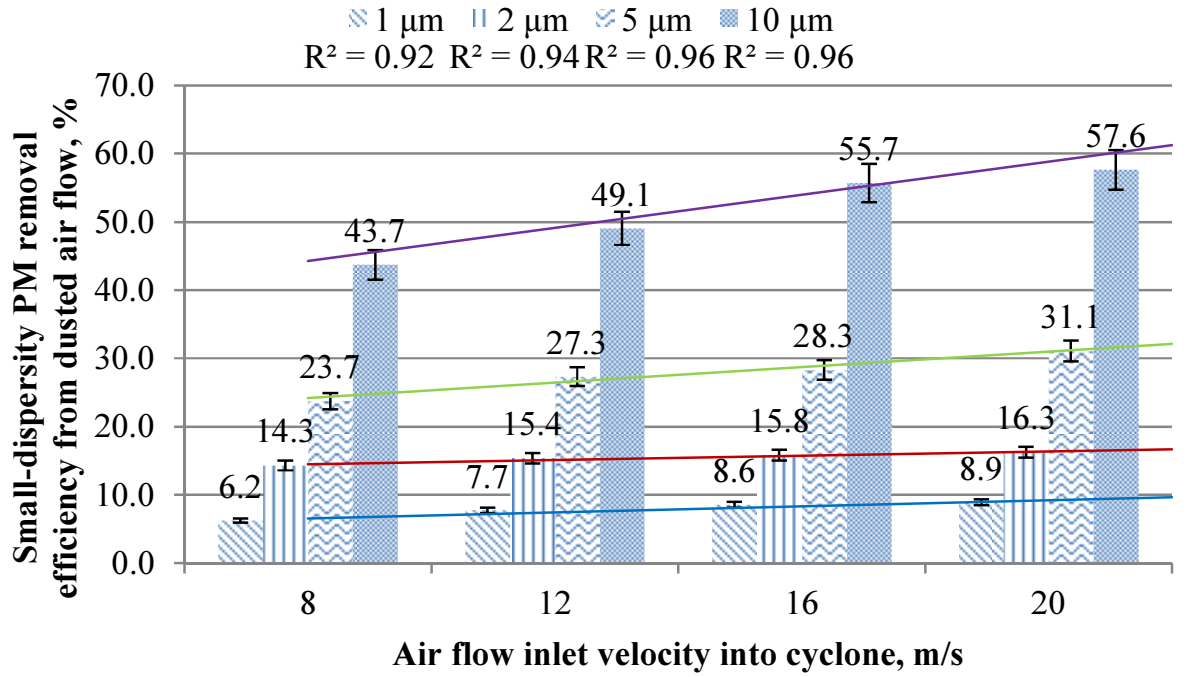

Fig. 5. Efficiency dependencies of removal of different size technical salt $\left(\rho=2100 \mathrm{~kg} / \mathrm{m}^{3}\right)$ PM from the airi $\mathrm{n}$ the spiral six-channel cyclone, under concentration of $2 \mathrm{~g} / \mathrm{m}^{3}$ and air flow inlet velocity $(8,12,16,20 \mathrm{~m} / \mathrm{s})$ 
As in the case at $2 \mathrm{~g} / \mathrm{m}^{3}$, significant changes in the efficiency observed for PM with $5 \mu \mathrm{m}$ and $10 \mu \mathrm{m}$ sizes. At $5 \mu \mathrm{m}$ PM the size of the largest removal efficiency change set changes in the inflow rate of $8 \mathrm{~m} / \mathrm{s}$ to $12 \mathrm{~m} / \mathrm{s}$, the efficiency increase of more than 1.15 times, and was achieved in $27.3 \%$ removal efficiency value. In all other cases, investigation of $1 \mu \mathrm{m}, 2 \mu \mathrm{m}$ and $5 \mu \mathrm{m}$ PM removal efficiency increased from $2.7 \%$ using $1 \mu \mathrm{m}$ PM up to $7.4 \%-5 \mu \mathrm{m}$ PM, increasing air flow into the cyclone inlet velocities from $8 \mathrm{~m} / \mathrm{s}$ to $20 \mathrm{~m} / \mathrm{s}$.

Clay PM from the sample with the lowest bulk density, the removal efficiency of the air flow results at $2 \mathrm{~g} / \mathrm{m}^{3}$ concentration of PM, presented in Figure 6.

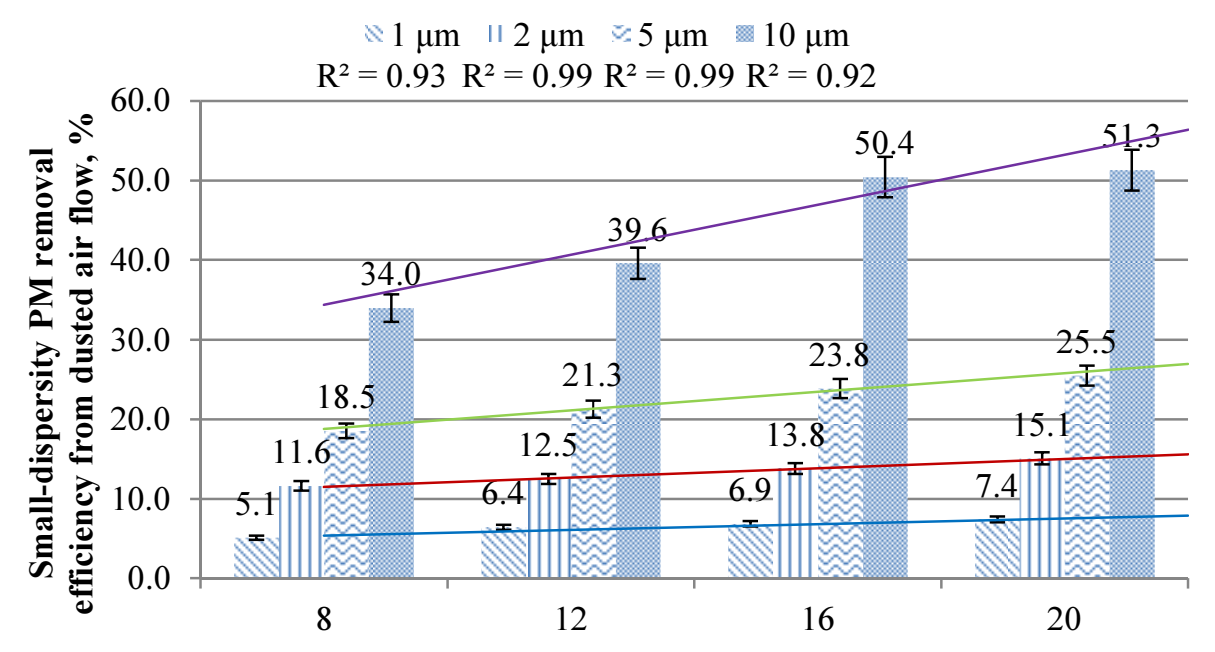

Air flow inlet velocity into cyclone, $\mathrm{m} / \mathrm{s}$

Fig. 6. Efficiency dependencies of removal of different size technical salt $\left(\rho=2100 \mathrm{~kg} / \mathrm{m}^{3}\right)$ PM from the airi $\mathrm{n}$ the spiral six-channel cyclone, under concentration of $2 \mathrm{~g} / \mathrm{m}^{3}$ and air flow inlet velocity $(8,12,16,20 \mathrm{~m} / \mathrm{s})$

As already examined cases, the use of glass and technical salt PM, removal efficiency increases with the PM concentration from $2 \mathrm{~g} / \mathrm{m}^{3}$ to $5 \mathrm{~g} / \mathrm{m}^{3}$ and inlet air flow velocity in the cyclone from $8 \mathrm{~m} / \mathrm{s}$ to $20 \mathrm{~m} / \mathrm{s}$ (Fig. 7). $1 \mu \mathrm{m}$ of clay $\mathrm{PM}$ removal efficiency $-5.1 \%$ at $2 \mathrm{~g} / \mathrm{m}^{3}$, the air flow rate $-8 \mathrm{~m} / \mathrm{s}$, and the air flow rate increases up to $20 \mathrm{~m} / \mathrm{s}-7.4 \%$.

Removal efficiency of $2 \mu \mathrm{m} \mathrm{PM}-11.6 \%$ was obtained at the minimum air flow rate $-8 \mathrm{~m} / \mathrm{s} .5 \mu \mathrm{m}$ and $10 \mu \mathrm{m}$ PM removal efficiency, respectively $-18.5 \%$ and $34 \%$. It may be noted that the removal of $5 \mu \mathrm{m}$ or larger in diameter of PM, removal efficiency was significantly increased growth of PM aerodynamic diameter of the analyzed air flow rates in the range of sizes, as well as other cases of PM (Fig. 2, Fig. 4).

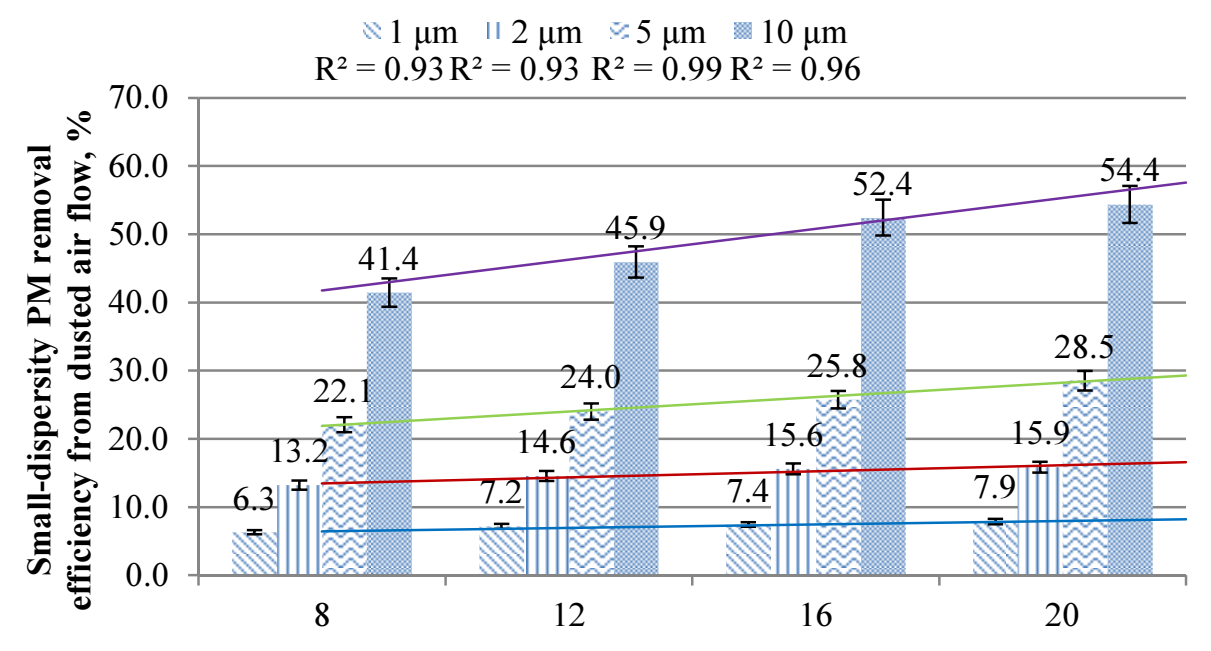

Air flow inlet velocity into cyclone, $\mathrm{m} / \mathrm{s}$

Fig. 7. Efficiency dependencies of removal of different size technical salt $\left(\rho=2100 \mathrm{~kg} / \mathrm{m}^{3}\right) \mathrm{PM}$ from the airi $\mathrm{n}$ the spiral six-channel cyclone, under concentration of $2 \mathrm{~g} / \mathrm{m}^{3}$ and air flow inlet velocity $(8,12,16,20 \mathrm{~m} / \mathrm{s})$

At a maximum of $20 \mathrm{~m} / \mathrm{s}$ inlet velocity to the cyclone, PM removal efficiencies of air traffic is highest. The biggest change between the efficiency observed for PM with $5 \mu \mathrm{m}$ and $10 \mu \mathrm{m}$ sizes. Inflow velocity changes from $12 \mathrm{~m} / \mathrm{s}$ to $16 \mathrm{~m} / \mathrm{s}$, $10 \mu \mathrm{m}$ PM removal efficiency of the air traffic increased 1.27 times, representing 10.8\% PM removal efficiency increases. The examination of the other PM sizes increased efficiencies of up to $3 \%$ increase in the inflow rate, the difference between efficiency values at $8 \mathrm{~m} / \mathrm{s}$ and $20 \mathrm{~m} / \mathrm{s}$ is the maximum speed of 1.5 times and researching $10 \mu \mathrm{m}$ PM size. 
At $5 \mathrm{~g} / \mathrm{m}^{3}$ clay PM removal efficiency obtained as compared with the cases at $2 \mathrm{~g} / \mathrm{m}^{3}$. Partition dependency is shown in Figure 7. The smallest size $-1 \mu \mathrm{m}$ of clay PM removal efficiency at a minimum air flow rate $-8 \mathrm{~m} / \mathrm{s}-6.3 \%$. The amount of PM at $2 \mathrm{~g} / \mathrm{m}^{3}$, removal efficiency - reduced by 1.2 times. $2 \mu \mathrm{m}$ PM removal efficiency of approximately 2.1 times greater than $1 \mu \mathrm{m}$ and PM ranging from $13.2 \%$ to $15.9 \%$ (Fig. 7). $5 \mu \mathrm{m}$ PM at high air flow rate, removal efficiency - up to $28.5 \%$, which is 3.6 times or $20.6 \%$ higher in terms of the maximum values obtained from the evaluation of $1 \mu \mathrm{m}$ PM removal efficiency. As in the case at $2 \mathrm{~g} / \mathrm{m}^{3}$, significant changes in the efficiency observed for PM with $5 \mu \mathrm{m}$ and $10 \mu \mathrm{m}$ sizes.

At $5 \mu \mathrm{m}$ PM the size of the largest removal efficiency change set changes from the inlet velocity of $16 \mathrm{~m} / \mathrm{s}$ to $20 \mathrm{~m} / \mathrm{s}$, the efficiency increase of $2.7 \%$, and $28.5 \%$ were achieved removal efficiency value. Study of PM with a size of $2 \mu \mathrm{m}$ found that an increase in air speed from $8 \mathrm{~m} / \mathrm{s}$ to $12 \mathrm{~m} / \mathrm{s}$, removal efficiency increased by more than 1.1 times. In all other cases, investigation of $1 \mu \mathrm{m}, 2 \mu \mathrm{m}$ and $5 \mu \mathrm{m}$ PM removal efficiency increased from 1.6\% using $1 \mu \mathrm{m}$ PM up to $6.4 \%-5 \mu \mathrm{m}$ PM, increasing air flow into the cyclone inlet velocities from $8 \mathrm{~m} / \mathrm{s}$ to $20 \mathrm{~m} / \mathrm{s}$.

Small-dispersed technical salt and clay PM in multi-channel cyclone removal efficiency of the air flow was reduced, compared with glass PM. Low levels of particulate removal efficiency could lead to lower PM densities, technical salt -1.2 times $\left(2100 \mathrm{~kg} / \mathrm{m}^{3}\right)$, and clay -1.5 times $\left(1700 \mathrm{~kg} / \mathrm{m}^{3}\right)$, and low concentrations of PM small-dispersed PM (from $1 \mu \mathrm{m}$ to $5 \mu \mathrm{m}$ ) per common mass (Table 1). The results of experimental studies indicate that a cyclone in the air flow rate of $8 \mathrm{~m} / \mathrm{s}$ to $22 \mathrm{~m} / \mathrm{s}$ better to remove $5 \mu \mathrm{m}, 10 \mu \mathrm{m}$ lower than the $1 \mu \mathrm{m}$ and $2 \mu \mathrm{m}$ PM.

Derksen [18] investigated small-dispersed PM removal efficiency and found that less than 4 microns PM cyclone dissipates. The researcher found that a key role in the separation process carried out by the turbulence. Small PM turbulence is dissipated after the cyclone and its most likely fall into the flow through the outlet pipe at the top. The bigger the PM are, the more they accumulate in the walls of the area from which (due to the gas flow gravity operation) they gradually move into the cyclone hopper.

Between the air flow rate, and to investigate PM concentrations and air cleaning efficiency established a strong linear relationship, as the coefficient of determination $\mathrm{R}^{2}$ is obtained close to 1 , while the minimum was 0.92 . Different dispersion glass PM removal efficiency was higher than the technical salt or clay PM removal efficiency. It can be argued that this may have been influenced, glass density of PM, which is greater than the technical salt and clay, but in different ways and consequently affecting the PM concentration and air flow rate.

Ukrainian scientists Serebryanskyy and Prijomov [19] found that the spiral cyclone wall at the end of the half-rings (air flow separation on site) formed PM dynamic barrier (PM aggregation) in which the PM is coagulating. It can therefore be assumed that at $16 \mathrm{~m} / \mathrm{s}$ to $20 \mathrm{~m} / \mathrm{s}$ inlet velocity to the cyclone and $5 \mathrm{~g} / \mathrm{m}^{3}$ small-dispersed concentration of PM is the ability to coagulate to form larger diameter PM. After separation of the peripheral part of the air flow coagulated PM fall into the hopper.

Cyclone air cleaning device applied to the contaminated particulate matter air cleaning, and pollutant PM catch degree is certainly the main and most important of all, of the performance indicators. Experimental studies of cyclone efficiency, analysis of the results obtained, it can be said that six-channel cyclone is suitable for efficient small-dispersed contaminated particulate matter from air (gas) flow. High cleaning efficiency ensures proper hygienic conditions for use in production, preventing unauthorized pollution emissions. Polluted air flow cleaned from PM, making it possible to apply precision air quality level required for facilities, jobs and production lines, ensuring the health, working capacity and atmospheric air quality.

\section{Conclusions}

1. Cyclone efficiency is $69 \%$ by removing $10 \mu \mathrm{m}$ of glass particulate matter, which bulk density is $2500 \mathrm{~kg} / \mathrm{m}^{3}$, with maximum $5 \mathrm{~g} / \mathrm{m}^{3}$ concentration and $20 \mathrm{~m} / \mathrm{s}$ air flow inlet velocity into cyclone. The bulk densities of technical salt particulate matter is $2100 \mathrm{~kg} / \mathrm{m}^{3}$ and clay particulate matter is $1700 \mathrm{~kg} / \mathrm{m}^{3}$ which are disposed respectively $57.6 \%$ and $54.4 \%$ efficiency.

2. Air flow inlet velocity changes from $8 \mathrm{~m} / \mathrm{s}$ to $20 \mathrm{~m} / \mathrm{s}$, the average removal efficiency increases to $1.6,1.5$ and 1.4 times at $2 \mathrm{~g} / \mathrm{m}^{3}$ appropriate testing glass particulate matter, clay and technical salt, and most occurring $1 \mu \mathrm{m}$ and $10 \mu \mathrm{m}$ sizes of particulate matter.

3. Multi-channel spiral cyclone may be removed from the air stream of finely divided - from $1 \mu \mathrm{m}$ to $5 \mu \mathrm{m}$ particulate matter, reaching $1 \mu \mathrm{m}-10.1 \%, 2 \mu \mathrm{m}-19 \%$ and $5 \mu \mathrm{m}-34.8 \%$ cleaning efficiency.

4. Experimental studies have shown that particulate matter removal efficiency from dusted air used multi-channel cyclone with curved channel increases with increasing particulate matter density, concentration - from $2 \mathrm{~g} / \mathrm{m}^{3}$ to $5 \mathrm{~g} / \mathrm{m}^{3}$, size of particulate matter - from $1 \mu \mathrm{m}$ to $10 \mu \mathrm{m}$ and the air flow speed - from $8 \mathrm{~m} / \mathrm{s}$ to $20 \mathrm{~m} / \mathrm{s}$.

\section{Acknowledgements}

The research has been conducted by implementing project "Application of spiral treatment device with a curvilinear channels for discrete phase treating" (Project No.: MIP-095/2012) of Projects of Research teams of development. Project is jointly funded by the Lithuanian Science Council. 


\section{References}

[1] Ingham, D. B.; Ma, I. 2002. Predicting the performance of air cyclones, Int. J. Energy Res 26: 633 $\square$ 652. http://dx.doi.org/10.1002/er.808

[2] Avci, A.; Karagoz, I. 2003. Effect of flow and geometrical parameters on the collection efficiency in cyclone separators, Journal of Aerosol Science 34: 937-955. http://dx.doi.org/10.1016/S0021-8502(03)00054-5

[3] Altmeyer S.; Mathieu V.; Jullemier S.; Contal P.; Midoux N.; Rode S.; Leclers J.P. 2004. Comparision of different models of cyclone prediction performance for various operating conditions using a general software, Chem. Eng. Prog. 43: 511-522. http://dx.doi.org/10.1016/S0255-2701(03)00079-5

[4] Kaya, F.; Karagoz, I. 2008. Performance analysis of numerical schemes in highly swirling turbulent flows in cyclones, Current Science 94(10): 12731278 .

[5] Blachman, W.; Lippmann, M. 1974. Performance characteristics of the multicyclone aerosol sampler, American Industrial Hygiene Association Journal 35: 311-326. http://dx.doi.org/10.1080/0002889748507040

[6] Saltzman, B. E.; Hochstrasser, J. M. 1983. Design and performance of miniature cyclones for respirable aerosol sampling, Environmental Science and Technology 17: 418-424. http://dx.doi.org/10.1021/es00113a011

[7] Vaitiekūnas, P.; Banaitytè, R. 2007. Modeling of motor transport exhaust dispersion, Journal of Environmental Engineering and Landscape Management 15(1): 39-46.

[8] Gimbun, J.; Chuah, T. G.; Fakhru'l $\square$ Razi, A.; Choong, T. S. Y. 2005. The influence of temperature and inlet velocity on cyclone pressure drop: A CFD study, Chem. Eng. Prog. 44: 7-12. http://dx.doi.org/10.1016/j.cep.2004.03.005

[9] Boysan, F.; Ayers, W. H.; Swithenbank, J. A. 1982. A fundamental mathematical modelling approach to cyclone design, Institution of Chemical Engineers 60: 222-230.

[10] Hoffmann, A. C.; Stein, L. E. 2002. Gas Cyclone and Swirl Tubes $\square$ Priciples, Design and Operation. Springer-Verlag, Berlin. http://dx.doi.org/10.1007/978-3-662-07377-3

[11] Meier, M.; Mori, M. 1999. Anisotropic behavior of the Reynolds stress in gas and gas $\square$ solid flows in cyclones, Powder Technology 101: 108-119. http://dx.doi.org/10.1016/S0032-5910(98)00162-4

[12] Hu, L. Y.; Zhou, L. X.; Zhang, J; Shi, M. X. 2005. Studies on strongly swirling flows in the full space of volute cyclone separator, AIChE Journal 51 (3): 740-749. http://dx.doi.org/10.1002/aic.10354

[13] Jakštonienè, I.; Serebryanskyy, D.; Vaitiekūnas, P. 2011. Experimental research on the work of centrifugal filter when eliminating solid particles from clinker cooling system, in The 8th International Conference „Environmental Engineering “: selected papers, May 19-20, 2011. Vilnius, Lithuania, Vol. 1. Vilnius: Technika, 134-138. ISBN 978-9955-28-263-1.

[14] Jakštonienè, I. 2012. Researches and development of cylindrical multichannel cyclone with adjustable half-rings. Doctoral thesis. Vilnius: Technika. 155 p.

[15] Raoufi, A.; Shams, M.; Kanani, H. 2008. CFD analysis of flow field in square cyclones, Powder Technology 1-9.

[16] Patterson, P. A.; Munz, R. J. 1996. Gas and particle flow patterns at room and elevated temperatures, Canadian Journal of Chemical Engineering 74: 213-221. http://dx.doi.org/10.1002/cjce.5450740206

[17] Vaitiekūnas, P.; Jakštonienè, I. 2010. Analysis of numerical modeling of turbulence in a conical reverse-flow cyclone, Journal of Environmental Engineering and Landscape Management 18(4): 321-328. http://dx.doi.org/10.3846/jeelm.2010.37

[18] Derksen, J. J. 2003. Separation performance predictions of a Stairmand high efficiency cyclone, AlChE Journal 49: 1359-1371. http://dx.doi.org/10.1002/aic.690490603

[19] Serebryanskyy, D.; Prijomov, S. 2007. Centrifugal filter. Patent: UA 78157. 